\title{
EDUCAÇÃO POPULAR NA PRÁTICA DOCENTE UNIVERSITÁRIA: EPISTEMOLOGIA PARA UMA CIÊNCIA PRÓPRIA
}

\author{
LA EDUCACIÓN POPULAR EN LA PRÁCTICA DOCENTE UNIVERSITARIA: \\ EPISTEMOLOGÍA PARA UNA CIENCIA PROPIA
}

\author{
POPULAR EDUCATION IN UNIVERSITY TEACHING PRACTICE: \\ EPISTEMOLOGY FOR ITS OWN SCIENCE
}

Maria do Socorro Pereira da SILVA ${ }^{1}$

RESUMO: Este artigo discute como a Educação Popular contribui para a formação de educadores populares que exercem o trabalho docente na universidade. A partir desse objetivo interpelamos: como a Educação Popular contribui para uma prática docente diferenciada na universidade, diante do paradigma eurocêntrico centrado no produtivismo para o capital? A abordagem qualitativa e a investigação-ação participante fundamentaram a concepção da pesquisa, para produção e coleta de dados: levantamento documental, entrevistas semiestruturadas, observação participante. O método dialético, como parte do próprio processo de pesquisa e da realidade social, permite analisar tensões, contradições, transformações e relações sociais de totalidade. Os aportes teóricos foram buscados em: Borda (1981), Freire (1996), Lefebvre (1983), Santos (2013), Streck (2014), entre outros. Os resultados apontam que a Educação Popular contribui para uma prática educativa docente comprometida com a reinvenção do conhecimento e da universidade, a partir de um para paradigma de ciência própria.

PALAVRAS-CHAVE: Educação popular. Prática docente. Universidade. Ciência própria.

RESUMEN: En este artículo se analiza cómo la Educación Popular contribuye a la formación de los educadores populares que ejercen la labor docente en la universidad. En base a este objetivo nos preguntamos: ¿cómo contribuye la Educación Popular a una práctica docente diferenciada en la universidad, frente al paradigma eurocéntrico centrado en el productivismo para el capital? El enfoque cualitativo y la investigación-acción participativa sustentaron la concepción de la investigación, para la producción y recolección de datos: encuesta documental, entrevistas semiestructuradas, observación participante. El método dialéctico, como parte del proceso de investigación y de la realidad social, permite analizar tensiones, contradicciones, transformaciones y relaciones sociales de totalidad. Se buscaron aportes teóricos en: Borda (1981), Freire (1996), Lefebvre (1983), Santos (2013), Streck (2014), entre otros. Los resultados muestran que la Educación Popular contribuye a una práctica docente educativa comprometida con la reinvención del conocimiento y la universidad, basada en un paradigma de la ciencia propia.

${ }^{1}$ Universidade Federal do Piaú (UFPI), Teresinha - PI - Brasil. Professora Adjunta da Universidade Federal do Piauí e Coordenadora do Núcleo de Estudos, Pesquisa e Extensão em Educação, Ciência Descolonial, Epistemologia e Sociedade (NEPEECDES). Doutorado em Educação (UFPI). ORCID: https://orcid.org/00000003-3877-2420. E-mail: socorroprof@ufpi.edu.br

RPGE- Revista on line de Política e Gestão Educacional, Araraquara, v. 24, n. 3, p. 1541-1558, set./dez. 2020. e-ISSN:1519-9029 
PALABRAS CLAVE: Educación popular. Práctica docente. Universidad. Propia ciencia.

ABSTRACT: This article discusses how Popular Education contributes to the formation of popular educators who exercise teaching work at the university. Based on this objective, we question: how does Popular Education contribute to a differentiated teaching practice at the university, in the face of the Eurocentric paradigm centered on productivism for capital? The qualitative approach and the participatory action research underpinned the conception of the research, for the production and collection of data: documentary survey, semi-structured interviews, participant observation. The dialectical method, as part of the research process and of the social reality, allows analyzing tensions, contradictions, transformations and social relations of totality. Theoretical contributions were sought in: Borda (1981), Freire (1996), Lefebvre (1983), Santos (2013), Streck (2014), among others. The results show that Popular Education contributes to a teaching educational practice committed to the reinvention of knowledge and the university, based on a paradigm of its own science.

KEYWORDS: Popular education. Teaching practice. University. Own science.

\title{
A universidade pública e a emergência da educação popular
}

As ideias que fundamentam uma prática educativa diferenciada de docentes na reinvenção da educação e na democratização da universidade têm uma longa trajetória, mas o novo dessa prática, na atualidade, é a educação popular. Diante disso, é necessário reafirmar as principais ideias de Educação Popular na Universidade, concordando com os princípios apresentado por Paulo Freire (2014) ao discutir a relação da educação popular na educação pública. Esse autor enfatiza:

\begin{abstract}
Nessa altura da reflexão, me parece importante deixar claro que a educação popular cuja posta em prática, em termos amplos, profundos e radicais, numa sociedade de classes, se constitui como um nadar contra a correnteza é exatamente a que, substantivamente democrática, jamais separa do ensino dos conteúdos o desvelamento da realidade. É a que estimula a presença organizada das classes sociais populares na luta em favor da transformação democrática da sociedade, no sentido da superação das injustiças sociais. [...] crítica também a natureza autoritária e exploradora do capitalismo (FREIRE, 2014, p. 118-120, grifo do autor).
\end{abstract}

A autoformação das classes populares, a auto-organização na luta por direitos, a criação e a articulação dos movimentos sociais, a luta anticapitalista local e global, a ampliação da democracia pela participação popular direta e indireta, em consonância com a luta pelo acesso à educação, a partir da educação popular constituem as marcas que asseguram os princípios da sociologia da epistexistência na produção do conhecimento situado na realidade concreta dos sujeitos. Portanto, a reconstrução das concepções de uma prática educativa universitária, 
fundamentada na relação entre teoria e prática social que envolve a totalidade das relações sociais, implica em pensar a sua própria centralidade, de modo que: "Podemos conceber uma universidade na diáspora que seja julgada de acordo com os seus efeitos sociais do conjunto e não por instalações físicas? Podemos articular esse caminho e conhecimentos permanentemente teórico com a prática?” (BORDA, 1981, p. 199, tradução nossa)². Essas questões têm sido ressignificadas por Boaventura Santos (2010):

A universidade no século XXI será certamente menos hegemônica, mas não menos necessária que foi nos séculos anteriores. A sua especificidade enquanto bem público reside em ser ela a instituição que liga o presente ao médio e longo prazo pelos conhecimentos e pela formação que produz e pelo espaço público privilegiado de discussão aberta e crítica que constitui. Por essas duas razões, é um bem público sem aliados fortes (SANTOS, 2010, p. 496).

A contribuição da Educação Popular como aliada da universidade somente tem sentido epistemológico, político e social se consideramos pertinente compreender essa relação a partir do seguinte questionamento: para qual projeto de sociedade queremos democratizar a universidade e a ciência? Essa questão é central para o nosso estudo, porque a própria concepção de educação popular se funda em uma perspectiva de construção de um projeto de sociedade com justiça social. Os estudos, dos pensadores clássicos aos mais atuais, que discutem a reinvenção/ressignificação da educação popular reconhecem que um dos princípios fundacionais dessa concepção educativa, é a intencionalidade política de construção de projeto de justiça social de matriz anticapitalista.

Dito isso, o desafio tem sido construir uma nova concepção de universidade e de ciência a partir do paradigma da Educação Popular. Na tentativa de superar o desperdício das experiências do Sul do Mundo, proposto por Santos (2011), e considerando a metodologia da sistematização das experiências como aporte metodológico na perspectiva de Holliday (2007) e de Lola (2003) como dimensões educativa e formativa do processo de investigação, é pertinente considerar que as experiências dos educadores populares no exercício docente tem contribuído para a construção de uma prática educativa universitária democrática. Em igual sentido, essa prática tem sido comprometida com a transformação da realidade social das classes populares dentro e fora da universidade.

${ }^{2}$ Podremos concebir una universidad en diáspora que se juzgue según sus efectos sociales de conjunto y no por facilidades físicas? Podremos articular, en esta forma y de manera permanente, el conocimiento teórico con la práxis? (BORDA, 1981, p. 199). 
Essas indagações nos inquietam na medida em que avança na universidade pública a presença de discentes e de docentes das classes populares que estão submetidos aos paradigmas teórico-metodológicos dominantes. Por isso, a necessidade de inventariar aportes epistemológicos alternativos na produção do conhecimento. Diante dessa realidade acadêmica, partimos do pressuposto de que os docentes presentes na universidade que viveram, ou ainda vivenciam os processos educativos e formativos da educação popular podem apresentar singularidades e dinâmicas próprias em sua prática educativa com repercussão no ensino, na pesquisa, na extensão na produção do conhecimento e de uma ciência alternativa.

Projetar essa discussão na universidade a partir dos aspectos pedagógicos da educação popular significa avançar na construção de um novo projeto de universidade a partir de um novo paradigma de produção do conhecimento. Para isso, enfatizamos acerca de qual concepção de conhecimento falamos ao tratar da relação entre Educação Popular e universidade pública, partindo da compreensão de que ambas são parte do mesmo processo de construção de uma educação pública, gratuita e de qualidade.

Nesse sentido, a prática educativa da Educação Popular tem ampliado seu cânone para além do meio popular e dos movimentos sociais populares, alcançando o espaço acadêmico como lugar de sua reinvenção educativa, epistêmica e social. Para isso, é necessário questionar não apenas o caráter da formação elitista, mas, à medida que as classes populares avançam no espaço acadêmico, diante da luta pela democratização do ensino universitário, é necessário repensar os conteúdos programáticos e a reaproximação da universidade do mundo dos discentes e dos docentes das classes populares.

A construção de uma matriz educativa enraizada na construção dos saberes populares comprometidos com a transformação da realidade social e contra o desperdício das experiências educativas e sociais difundida no interior dos movimentos e no processo de organizações das classes populares na sociedade civil. Essa opção político-pedagógica tem implicado em repensar a centralidade da universidade como estrutura social produtora do conhecimento no avanço do campo da Educação Popular nesse espaço do conhecimento e na ciência.

A influência indireta dos processos de formação da Educação Popular contribui para que os educandos e os educadores retomem sua vida acadêmica formal. Considerando os educadores populares que optaram pelo exercício docente na universidade pública, buscamos identificar as marcas da prática educativa da Educação Popular no processo de formação e de qualificação profissional e cidadã dos educadores-docentes. E diante desse itinerário, como a repercussão da prática docente influência o ensino, a pesquisa e a extensão na produção de uma epistemologia do conhecimento alternativo na universidade. 


\section{Concepção de educação popular na universidade: uma construção epistemológica dissidente}

Nesse sentido, evidenciamos como a educação popular influenciou na formação dos educadores docentes para atuação no mundo acadêmico, analisando sua incidência procurando encontrar as marcas da Educação Popular no ensino, na pesquisa e na extensão, aprofundando a ideia de projeto de universidade e de prática educativa que apostam no exercício docente e como concebem a relação de interconhecimento entre saberes populares e saberes acadêmicos.

O vínculo com a educação popular é pelos educadores-docentes como dimensão importante no fortalecimento de sua prática educativa universitária e de sua relação com as classes populares. Essa opção política tem assegurando elementos metodológicos e epistemológicos diferentes do paradigma hegemônico de produção do conhecimento na universidade. Nesse aspecto, há intencionalidade político-pedagógica da Educação Popular na formação de educadores populares que estejam em sintonia com a realidade social dos sujeitos e com a construção de um projeto de sociedade com justiça social:

Ser educador popular é ter uma prática educativa fundamentada nos valores, na cultura, nos saberes do povo. É se reconhecer no mundo e usar os conhecimentos diversos para praticar a transformação social. Pensar o papel do educador e da educadora popular não tem sido uma tarefa somente das instituições formais de ensino, como as universidades, os institutos entre outros, que trazem um conhecimento sistematizado, científico a respeito do papel do educador. Esse desafio de pensar o papel do educador tem sido uma preocupação e necessidade dos movimentos sociais, das organizações civis, dos grupos diversos, que buscam articular a ação formativa com a transformação da sociedade, através de ações e práticas coerentes com os projetos de mudança social (EQUIP, 2015).

A contribuição da Educação Popular para o processo de formação dos educadores populares “[...] é a que capacita suas professoras cientificamente à luz dos recentes achados em torno da aquisição da linguagem, do ensino, da escrita e da leitura. Formação científica e clareza política [...]”' (FREIRE, 2014, p. 119, grifo do autor). A EQUIP está empenhada com a formação de um intelectual popular que esteja comprometido com a construção da justiça social junto àqueles que mais precisam sentir sua condição humana ser erguida de dignidade, uma vez que "Somos todos vocacionados para ser mais e jamais estamos condenados a repetir o que já somo. Enquanto seres inacabados, estamos em busca de novas possibilidades e podemos realizar algo que hoje apenas é sonho, mas pode tronar-se realidade ser uma utopia possível" (STRECK, 2010, p. 18, grifo do autor). Por isso, um educador deve manter sua curiosidade epistemológica na realidade social buscando novas sínteses como progresso de análise, superando o relacionamento oposto entre teoria e prática, universidade e sociedade, saberes populares e 
saberes acadêmicos, entre o que é ciência e o que não é, na construção de uma vida com dignidade

Nesse sentido, a construção da identidade profissional dos educadores-docentes na universidade passa pela afirmação de seus aportes teóricos, pela sua concepção de educação e de projeto de sociedade, a partir do testemunho vivencial desses sujeitos junto às lutas das classes populares. De modo, que a prática docente seja substanciada pela matriz do conhecimento da realidade social que envolve a universidade e o projeto de sociedade que se empenha em construir, ou seja, "Do ponto de vista do cientista, o conhecimento das realidades locais torna-se tanto mais rico e útil quanto mais se relaciona com a compreensão e a autoridade da vivência pessoal. Autoridade científica e intuição que provem do contato com a vida real[...]" (BORDA, 2004, p. 715). Essa base de formação dos educadores-docentes garante a atualização de sua consciência para uma atuação política mais sistemática e organizativa na sociedade.

Nesse sentido, a produção intelectual dos educadores-docentes está comprometida com a visibilidade dos sujeitos, dos saberes e de seus contextos sociais como matriz epistemológica contra-hegemônica e de intervenção para transformação da realidade, articulando a vida social à vida acadêmica como parte das relações sociais de totalidade que envolvem a universidade com o mundo real. A contribuição da Educação Popular para a compreensão de uma produção do conhecimento sobre a realidade social é um dos grandes legados dos processos formativos da EQUIP que impactam na vida profissional dos educadores-docentes.

Desse modo, o papel do educador-docente deve ser de um sujeito cidadão que pertence a uma sociedade em que os processos sociais ocorrem simultaneamente dentro e fora da universidade e que, portanto, está situado social e historicamente diante do mundo, como analisa Fernandes (1989, p. 164), ao dizer que o professor deve estar em sintonia com as aspirações políticas que implicam em mudança social:

O professor não deve estar alheio à dimensão. Se ele quer mudança, tem que realizá-la nos dois níveis - dentro da escola e fora dela. Tem que fundir seu papel de educador ao seu papel de cidadão - e se for levado, por situação de interesses e por valores, a ser um conservador, um reformista ou um revolucionário, ele sempre estará fundindo os dois. Este debate, hoje, tem uma grande atualidade, porque a cultura cívica agora deixa de ser um elemento mistificado e mistificador.

Considerando esse pensamento, na Educação Popular, a participação ativa dos educadores nas transformações sociais constitui o elemento principal de sua prática educativa como dimensão de fortalecimento de sua presença na defesa de um projeto de sociedade mais junta. Nesse sentido, a concepção cívica de educação ligada ao mundo da vida é resultado 
concreto de sua intervenção no mundo da escola e no mundo da sociedade. Considerando essa leitura, nos importamos de compreender o conceito de educador popular na prática educativa universitária dos educadores-docentes e sua contribuição para uma nova concepção de ciência fora dos conhecimentos dominantes na universidade.

Tabela 1 - Incidência da educação popular na prática educativa dos educadores populares na universidade

\begin{tabular}{|c|c|}
\hline Sujeitos & Concepção de Educação Popular \\
\hline $\begin{array}{l}\text { Educadora } \\
\text { Social }\end{array}$ & $\begin{array}{l}\text { Então, eu diria assim: que não foi o fato de trabalhar com educação popular que me levou à } \\
\text { universidade, mas foi na universidade que eu descobri que eu podia ser uma educadora } \\
\text { diferente, que eu podia ser uma provocadora e que eu podia fazer uma prática } \\
\text { pedagógica diferente, uma prática pedagógica libertária, no sentido bem freireano. }\end{array}$ \\
\hline $\begin{array}{l}\text { Educadora } \\
\text { Gênero }\end{array}$ & $\begin{array}{l}\text { Eu considero que quase toda a minha prática docente, hoje, ela sofre influência direta } \\
\text { do processo de formação da Educação Popular [...] E esse processo da Educação } \\
\text { Popular, ele influencia muito, mais do que o próprio conhecimento adquirido na } \\
\text { universidade, como eu sempre falo. }\end{array}$ \\
\hline $\begin{array}{l}\text { Educador do } \\
\text { Campo }\end{array}$ & $\begin{array}{l}\text { A gente tenta desenvolver uma prática educativa que seja mais emancipadora, uma } \\
\text { prática educativa que procure despertar os alunos, os sujeitos para essa ação política na } \\
\text { sociedade. [...] Eu acho que uma das principais contribuições, assim, uma marca para mim, } \\
\text { ela passa pela forma como a gente vê o outro e lida com o outro, em uma perspectiva de } \\
\text { fraternidade, de amorosidade, de respeito, de humanidade, eu acho que é algo muito } \\
\text { forte em mim, na minha formação. }\end{array}$ \\
\hline $\begin{array}{l}\text { Educador } \\
\text { Trabalho }\end{array}$ & $\begin{array}{l}\text { O eixo da minha pedagogia na universidade é o de exercitar a capacidade de pensar e } \\
\text { exercitar a capacidade de pensar criticamente. [...] como também, para questionar os } \\
\text { status quo. Então, é um exercício de construção de pensamento crítico, isso é o que me } \\
\text { pauta na atividade acadêmica. }\end{array}$ \\
\hline
\end{tabular}

Fonte: Entrevistas orais para a pesquisa (2016)

A compreensão da prática educativa comprometida com a formação crítica e transformadora dos discentes significa a superação da lógica da reprodução do conhecimento que induz a uma consciência imersa, a uma apatia cognitiva e a condições de alienação. Desse modo, os educadores-docentes compreendem que o desenvolvimento de prática educativa na universidade passa pela valorização dos discentes como sujeitos de atitude e produtores do conhecimento, como parte e totalidade de uma realidade acadêmica libertadora e diferenciada.

Diante dessa prática educativa os sujeitos em processo de ensino-aprendizagem desenvolvem um nível de curiosidade epistêmica que fortalece a produção do conhecimento, que não se encerra em um monólogo intelectualizado do docente, cujo conhecimento não tem razão de ser para vida discente, e por vezes, para próprio sujeito formador.

O interconhecimento entre discentes e docentes são dois mundos complementares que, pela produção do conhecimento, encontram as relações sociais fazendo surgir um mundo real dentro do espaço acadêmico e fora dele. Tal encontro subjaz a ideia de conhecimento como idealismo que se restringe apenas ao campo da abstração, marcado pelo encontro entre o saber popular vivenciado com os saberes científicos, consolidam cada vez mais a prática educativa 
que reencontra o mundo da teoria com o mundo da prática como possibilidade de produção de um pensamento alternativo de conhecimento em seu conjunto das relações, como proposto por Lefebvre (1983, p. 235):

A teoria emerge da prática e a ela retorna. A natureza se revela a nós pela prática, pela experiência; e tão-somente pela prática é que dominamos de modo efetivo. A prática, portanto, é o momento de toda teoria: momento primeiro e último, imediato inicial e o retorno ao imediato. E vice-versa, a teoria é o momento da prática desenvolvida, daquela que supera a simples satisfação dos carecimentos imediatos.

Essa prática educativa desperta os sujeitos para a autoconsciência, a consciência crítica em que o próprio ato de conhecer encontra os sentidos das relações sociais. Isso gera a curiosidade e o estudo criterioso da realidade social do sujeito que a partir do interconhecimento, imprime novos sentidos, novas causas e formas de atuação na sociedade, superando a relação docente que impõe seu saber como poder, subalternizando o poder do senso comum na construção de um novo conhecimento; uma prática educativa que rejeita a relação autoritária entre docente e discente, retoma a horizontalidade de saberes na afirmação da epistexistência dos sujeitos populares na produção do conhecimento, como proposto por Paulo Freire (2014, p. 120), ao discutir a relação da Educação Popular na Escola Pública:

É a que respeita os educandos, não importa qual seja sua concepção de classe. [...] É a que, em lugar de negar a importância dos pais, da comunidade, dos movimentos populares na escola, se aproxima dessas forças com as quais aprende para elas poder ensinar também. [...] É a que supera os preconceitos de raça, de classe, de sexo e se radicaliza na defesa da substantividade democrática. Por isso mesmo se bate por uma crescente democratização nas relações que se travam na escola e das que se estabelecem entre a escola e o mundo fora dela $[\ldots]$.

Colocar em prática essa concepção de educação é um desafio, suscitado várias vezes no relato dos educadores populares que exercem a docência na universidade pública. Apontam que ainda predomina a hegemonia de um pensamento conservador marcado por propostas pedagógicas fechadas que encerram o conhecimento em si próprio, sem relação concreta com a vida na sociedade, reproduzindo uma ideia de educação destituidora do ser cognitivo, como afirma a Educadora Social (2016): “[...] é uma educação bancária, que é uma educação reprodutora, não é uma educação para formar sujeitos, é uma educação para que você domine os conceitos e que seja capaz de reproduzir conceitos. Eu não quero isso do aluno!" Os demais educadores caracterizaram essa perspectiva educativa na universidade como uma "visão 
enciclopedista"; "uma educação muito tradicional”, ou, ainda, como afirma o Educador Político (2015):

Na universidade é diferente, então, você tem uma turma que você trabalha com ela em quatro meses e você ver a turma duas vezes por semana apenas. Num curso da EQUIP, você fica cinco dias em regime de internato com o grupo todo durante três quatro vezes por ano, então, na universidade além de ser mais disperso a turma, você também tem um conteúdo que ele é mais programático e pragmático, então, faz parte de um plano político pedagógico do curso, do qual você não pode fugir muito, embora tenha disciplinas que você pode trabalhar e preparar, mas você tem que trabalhar com aquelas ementas do curso, você não pode deixar de considerar as ementas do curso e você tem também que lidar com a discussão que não está muito preocupado com o aspecto de formação de sujeito para a transformação da realidade. $O$ campo da universidade é muito mais voltado para a formação do profissional para o mercado de trabalho [...].

Outro desafio é enfrentar a cultura do medo discente fortemente difundida pela concepção de educação colonial, autoritária e eurocentrada, ao longo da história, marcada pela relação do saber como poder, ou seja, é o docente que tem o saber, portanto, tem o domínio da fala como relação de poder. Isso tem sido um dos limites para uma maior abertura discente à prática educativa inovadora, como relata a Educadora Social (2015): "Porque o aluno, ele vem no sistema como um domesticado, ele já vem domesticado, né? Então, o aluno tem medo de falar, o aluno tem medo de se posicionar, o aluno tem medo de perguntar na verdade". Quando os discentes encontram docentes que se orientam por outra perspectiva educativa, sobretudo no campo da educação popular, a tensão entre docente-discente é recorrente.

Entretanto, essa tensão deve ser considerada como parte do processo de construção de uma prática educativa inovadora, uma vez que o educador-docente não detém a verdade absoluta, cuja metodologia do ensino é inegociável, reconhecer isso, significa compreender que sempre é possível apreender no ato de realização de sua prática docente na universidade. A amorosidade e o respeito talvez devam ser a maior contribuição da Educação Popular para uma prática educativa na universidade. A amorosidade como capacidade de alteridade, da indignação diante da injustiça, da desvalorização da vida, de toda forma de desamor, de desumanização do ser.

\section{Educação popular no ensino, pesquisa e extensão na universidade: prática docente diferenciada}

As marcas da Educação Popular na prática educativa universitária apostam em outra forma de educação, como podemos verificar nos relados dos educadores, aos afirmarem sua 
concepção de educação e a possibilidade do diálogo entre saberes populares e saberes científicos no desenvolvimento de novos modos de produção do conhecimento a partir do ensino universitário:

Tabela 2 - A prática educativa dos educadores populares no ensino universitário

\begin{tabular}{l|l}
\hline Eixo 5 & \multicolumn{1}{|c}{$\begin{array}{l}\text { E... Em geral, os educadores têm medo dos seus educandos, porque eles não têm } \\
\text { aquela história que você não dá asa pra formiga. E é esse medo que os educadores } \\
\text { têm que dificulta essa aproximação, porque a educação tem que ser uma } \\
\text { aproximação, ela tem que ser amorosa. Paulo Freire dizia a isso: "Eu amo a toda a } \\
\text { gente. Eu amo todos os seres." Então, não existe educação que não transforme o } \\
\text { ser humano, você tem que se transformar, tem que se "transformar", no sentido } \\
\text { que você tem que olhar para aquela pessoa, aquele sujeito que tá ali como um } \\
\text { ser humano que precisa ser ouvido [...] É isso que Paulo Freire chamava de } \\
\text { amor, esse amor que acolhe, que escuta. }\end{array}$} \\
UFPE & $\begin{array}{l}\text { Eu me considero um professor crítico que trabalho com uma realidade crítica, } \\
\text { com a teoria crítica. Não me considero um professor que trabalha com o } \\
\text { conformismo e com a, digamos, o tradicionalismo e nem muito bem com as } \\
\text { correntes de direita, mas também não me considero um doutrinário. Eu não me } \\
\text { considero formando militante dentro da universidade, eu me considero } \\
\text { formando sujeitos críticos e pensadores da realidade social. }\end{array}$ \\
\hline Educador \\
Político
\end{tabular}

Fonte: Entrevistas orais para a pesquisa (2016)

Esses relatos dos educadores populares no exercício docente apontam para algumas características de sua pratica educativa na universidade, como: afirmação da autonomia na 
construção de sua proposta político-pedagógica em seus planos de ensino; compromisso com a formação crítica dos discentes; participação ativa dos discentes na produção do conhecimento; leitura da realidade social para trabalhar os conceitos teóricos; experiências concretas como suporte para fundamentação teoria dos conhecimentos, quando propõe o desenvolvimento de aulas de campo; respeito aos discentes como sujeitos históricos e com a realidade que vivenciam.

Ainda nesse itinerário educativo, outro compromisso importante dos educadoresdocentes tem sido a atualização dos conteúdos em diálogo com a realidade, em razão dos momentos conjunturais ou estruturais da sociedade, nas discussões de sala de aula; a compreensão do interconhecimento, de que são portadores de um tipo de conhecimento e que os discentes têm um acumulo de conhecimento de sua prática social e de suas experiências; a amorosidade no ato de educar; o ensino crítico e não doutrinário que implica na circulação da palavra criando aproximações na relação docente-discente, dentre outras.

Essas características revelam as marcas de uma prática educativa adquirida pelos educadores no meio popular, desse modo, “[...] a educação popular possibilita o diálogo de saberes populares, da cultura popular com os saberes/conhecimentos produzidos e sistematizados socialmente [...] são saberes de uma epistemologia que une ação-reflexão.” (STRECK et al., 2014, p. 93). A prática educativa universitária se altera, como também se transformam os educadores docentes que, comprometidos com uma formação cidadã dos discentes, empenham-se em fazer do ato educativo um caminho para uma consciência crítica e transformadora desses sujeitos.

O desenvolvimento de aprendizagens recíprocas entre docente e discentes, a partir do diálogo entre teoria e prática social, em experiências concretas na sociedade, apontam para a construção de novos conhecimentos, de novas práticas educativas e de formas de leituras da realidade social. O educador popular, no exercício docente, retoma seu papel de potencializador do caráter social da universidade e, ao mesmo tempo, propicia condições para que os discentes como sujeitos históricos, ativem sua curiosidade epistemológica para produção de sua cidadania educativa. A criatividade metodológica na prática educativa dos educadores-docentes constitui uma das marcas da Educação Popular como concepção educacional de desvelamento da realidade social.

Em igual sentido, contribui para a construção de instrumentos político-pedagógicas alternativos no ensino universitário comprometido com uma concepção de ensino em sintonia com as questões sociais. Essas metodologias asseguram novas formas de inteligibilidade da prática social, ou seja, tanto os discentes quanto os docentes e os sujeitos dos movimentos 
sociais aprendem como ensinam, situados em suas vivências, encontram suas próprias contradições e reinventam suas experiências e suas visões de mundo.

O lócus da prática social como aporte para os conceitos e os conteúdos que se transformam em novos sentidos e significados, o que não seria possível somente pelos estudos dos conhecimentos teóricos de sala de aula. Por isso, a importância de uma concepção de ensino universitário que articule os saberes populares aos saberes científicos na dinâmica de suas incompletudes, que se abrem para o novo, o desconhecimento, o imaginário e para o sensível. A inteligibilidade entre o popular e o científico são formas de vivenciar a ciência na produção de um conhecimento prudente para uma vida decente (SANTOS, 2010). Nessa perspectiva, a universidade deve estar comprometida com a formação de indivíduos que, em seus conhecimentos, produzam para o bem comum e para uma vida justa, como afirma Borda (2004, p. 720):

Para apoiar estes processos, necessitamos de universidades democráticas e altruístas que estimulem a participação ativa dos estudantes na procura de novos conhecimentos e, nessa medida, considerem a investigação como ferramentas pedagógicas do maior valor, como base de uma autonomia acadêmica. Que tenham como tarefa prioritária a consolidação de um ambiente cultural que propicie a criatividade durante todas as etapas de formação que contribuam para o processo de reconstrução social e o bem-estar das maiorias desprotegidas da população.

A contribuição educadores-docentes a partir das experiências vivenciadas em educação popular no desenvolvimento de novas metodologias pode contribuir significativamente para uma perspectiva de ensino que articule a teoria à prática como possibilidade para transgredir os padrões de ensino-aprendizagem da concepção de educação eurocêntrica, visto que "Todo e qualquer projeto pedagógico, ou proposta de educação, e todo e qualquer ato educativo são, fundamentalmente, ações políticas [...]” (STRECK, 2014, p. 94). Apesar do empenho dos educadores-docentes no desenvolvimento de alternativas metodológicas para uma prática educativa contextualizada, eles enfrentam os limites institucionais das lógicas do ensino padrão, da resistência dos discentes para a inovação da prática educativa. Enfrentam desafios que se ampliam na pesquisa e na extensão, como podemos ver na discussão a seguir. 
Tabela 3 - Elementos da concepção de pesquisa/extensão dos educadores-docentes na universidade

\begin{tabular}{|c|c|}
\hline Sujeitos & Pesquisa e Extensão na Universidade \\
\hline $\begin{array}{l}\text { Educador } \\
\text { Político }\end{array}$ & $\begin{array}{l}\text { [...] o projeto mais recente que eu atualmente trabalhei orientando foi um projeto de } \\
\text { uma aluna que trabalha com o orçamento participativo e que ela estudou o } \\
\text { orçamento participativo da cidade de Teresina. Na verdade, não se chama orçamento } \\
\text { participativo, se chama Orçamento Popular de Teresina. Então, esse trabalho dessa } \\
\text { aluna que durou dois anos, ela fez uma leitura crítica dos últimos dez anos daquela } \\
\text { prática social, mas ela defendeu a dissertação dela, concluiu esse trabalho e, atualmente, } \\
\text { estou orientando quatro projetos: um trabalha sobre a questão da, digamos, das novas } \\
\text { tecnologias e transparências na escola, como fazer uma gestão democrática e } \\
\text { participativa nas escolas do ensino fundamental a partir da lei da transparência e das } \\
\text { tecnologias que se tem na atualidade; Um outro projeto que é um projeto sobre os } \\
\text { movimentos (sociais) do Passe Livre em Teresina dos anos } 2011 \text { e } 2012 \text {; esses projetos, } \\
\text { eles também remetem para uma outra discussão que é a discussão muito mais da } \\
\text { cidadania, da questão direitos da cidadania, da questão da formação dos indivíduos, } \\
\text { de como a sociedade está atualmente transformando, mudando, então, um pouco } \\
\text { nessa linha mais global, geral da sociedade. }\end{array}$ \\
\hline $\begin{array}{l}\text { Educadora } \\
\text { Gênero }\end{array}$ & $\begin{array}{l}\text { Na universidade, eu tento manter a minha linha de pensamento, de ação, baseada na } \\
\text { Educação Popular e me articulando com os professores que também pensam dessa } \\
\text { forma. Nesse sentido, a minha parte de ensino, de pesquisa e de extensão é toda } \\
\text { voltada nessa perspectiva. Com relação, por exemplo, à atuação na Universidade com } \\
\text { relação a projetos alternativos, a gente também se articula para, por exemplo, apresentar } \\
\text { projetos: Pedagogia da Terra, outros projetos que estão envolvidos. A Educação Popular, } \\
\text { por exemplo, nós oferecemos uma especialização, que tinha como princípio a } \\
\text { gratuidade para os alunos, que trabalha com Educação Popular, Direitos Humanos } \\
\text { e Movimentos Sociais. Então, foi uma perspectiva também que caracteriza um pouco } \\
\text { do compromisso da gente com essa questão da Educação Popular e com a luta das } \\
\text { organizações sociais do movimento popular. } \\
\text { Os projetos de extensão, por exemplo, são nessa perspectiva da linha de gênero, } \\
\text { especificamente, e também na linha da Educação Popular porque trabalha com } \\
\text { grupo de mulheres, com comunidades, são esses eixos. }\end{array}$ \\
\hline $\begin{array}{l}\text { Educador do } \\
\text { Campo } \\
\text { UFPI }\end{array}$ & $\begin{array}{l}\text { Nós atuamos no Núcleo de Pesquisa, de Estudos e Extensão em Educação do Campo } \\
\text { (NUPECAMPO) No Núcleo, a gente trabalha com o projeto de extensão. Eu estou } \\
\text { coordenando um Projeto de Formação de Educadores no Campo, que a gente faz um } \\
\text { trabalho em parceria com algumas organizações sociais, com a Secretaria Estadual da } \\
\text { Educação e com as Secretarias Municipais de Educação. E aí a gente tenta, nesse trabalho, } \\
\text { fazer toda uma discussão que a gente iniciou e aprendeu a fazer dentro das } \\
\text { organizações sociais. Então, é fazer uma problematização da realidade, dessa } \\
\text { concepção do campo, dessa concepção de desenvolvimento, que está sendo imposto } \\
\text { para o campo, tentando, a partir disso, fomentar o desenvolvimento de uma educação } \\
\text { crítica, de uma educação emancipadora, tendo os ideais freireanos como elementos } \\
\text { norteadores desse trabalho de formação e também de implementação dessas práticas } \\
\text { educativas. }\end{array}$ \\
\hline
\end{tabular}

Fonte: Entrevistas orais para a pesquisa (2016)

A pesquisa tem sido um instrumento fundamental para incrementar cientificamente tanto o ensino como a extensão. A Educação Popular tem se ocupado de projetar modos alternativos de realização de investigação da realidade social, em que o ato de pesquisar implica em processos formativos e em ação/intervenção sobre a prática investigada. Nesse sentido, é 
importante considerar a possibilidade do ensino e da extensão como instrumentos metodológicos e pedagógicos do processo de investigação com os quais a pesquisa se realiza.

Neste aspecto, Educação Popular a partir de sua forma de investigação da realidade social, inaugurou novos conceitos e diferentes conteúdos na vida acadêmica a partir das práticas sociais dos sujeitos coletivos, notadamente dos movimentos sociais, ao construir alternativas de políticas sociais, reordenado a própria lógica do Estado para os graves problemas sociais, obrigando a ciência hegemônica a reconhecer e a legitimar seus conhecimentos em muitas áreas das ciências. As metodologias participativas gestadas no seio das práticas educativas da Educação Popular asseguram novas formas de desenvolver a pesquisa em compromisso com o desocultamento das realidades sociais de opressão, com as formas veladas de discriminação e de fascismo na sociedade; ao mesmo tempo inauguram novos instrumentos de questionamento das desigualdades estruturais impostas ao mundo pelo sistema capitalista, como analisa Santos (2013), ao discutir que essas novas metodologias têm sua própria racionalidade como dimensão de pesquisa na vida universitária:

A pesquisa-ação e a ecologia dos saberes são áreas de legitimação da universidade que transcendem a extensão uma vez que tanto atuam ao nível desta como no nível da pesquisa e da formação. A pesquisa-ação consiste na definição e execução participativa de projetos de pesquisa, envolvendo comunidades e organizações sociais populares, há braços com problemas cuja a solução pode beneficiar dos resultados da pesquisa (SANTOS, 2013, p. 471).

Dentro dessa perspectiva, a contribuição da Educação Popular avança no compromisso com alguns aspectos na forma de desenvolver pesquisa e extensão, como afirmam os educadores-docentes, dentre os quais, destacamos: compromisso com a participação ativa dos sujeitos como protagonistas dos conhecimentos e do desenvolvimento da pesquisa; devolução sistemática da pesquisa em atividades formativas realizadas em parceria com os sujeitos da pesquisa; problematização da realidade social nos contextos do estudo; interesse por pesquisa em contextos de luta, resistência e desenvolvimento de novas técnicas e instrumentais de acesso a direitos e à justiça; pesquisas em que os sujeitos investigadores sejam da mesma origem dos contextos investigados, a exemplo da pesquisa participante; investigação dos sujeitos coletivos como os movimentos sociais Há, ainda, projetos de extensão como aqueles ligados à história do feminismo, que implica na formação processual das mulheres para a luta por direitos e contra as formas de violência e o machismo; do acesso à formação universitária como a oferta de cursos de especialização para sujeitos populares que atuam nos movimentos sociais do campo e da cidade, etc. É inegável a contribuição das marcas da Educação Popular na realização de pesquisas e da extensão na 
construção de uma sociedade mais justa, sobretudo para os sujeitos sociais que estiveram historicamente fora da vida universitária, em razão dos processos de exclusão e de desigualdades sociais.

Nesse sentido, considerando que a maioria dos educadores-docentes está ligada à graduação e à pós-graduação, orientando diversos temas de pesquisa, majoritariamente ligados a ciências humanas, sociais e sociais aplicadas, temos nos questionado porque ainda predomina uma fragmentação nos modos de produção do conhecimento na universidade, mesmo por esses educadores. Ou seja, dificilmente há intercâmbio ou troca de experiências entres as pesquisas, mesmo estudando temáticas semelhantes e estando ligadas a uma única linha de pesquisa; pelo contrário, tem sido um processo extremamente solitário. Nos núcleos de estudos e pesquisas, a interdisciplinaridade tem sido um desafio para sua realização em plenitude.

Diante desse acelerado modo de produção acadêmica, outro limite que analisamos é que, mesmo os educadores-docentes, que orientam pesquisas nessa grande área das ciências sociais, encontram limites para articular formas de interconhecimento entre os estudos e as pesquisas que realizam, ainda que pertencendo à mesma universidade. Por um lado, esse questionamento parte da compreensão de que, diante do avanço do capitalismo no mundo e da forma de produção acadêmica para consolidação desse projeto de sociedade desigual e injusta, necessitamos de uma ação de intervenção acadêmica e social mais comprometida com a discussão das graves questões sociais e dos níveis de alcance das relações de totalidade que resultam na constituição de um modelo de sociedade.

Por outro lado, ao apostar nos diálogos entre as pesquisas e nos resultados que apontam, podemos apresentar níveis de articulação do conhecimento para um questionamento mais sistematizado e qualificado, desocultando a realidade social, como, por exemplo: o acesso à melhoria da mobilidade urbana leva à discussão das péssimas condições do sistema de transporte público; as formas de mobilização popular e estudantil na luta pela melhoria do transporte público apresentam novas demandas nas discussões do orçamento popular, das condições do trabalho e da precarização; das políticas sociais; das políticas educacionais para/do campo, enfim, precisamos dar inteligibilidade à articulação dos saberes entre os temas das pesquisas como condição de aprofundar uma intervenção social mais qualificada por parte dos pesquisadores - orientadores ou investigadores - como parte do mesmo processo de investigação.

Nesse sentido, é preciso que o diálogo entre saberes populares e saberes científicos ocorra dentro da própria prática educativa da pesquisa e da extensão no âmbito do espaço acadêmico, aproximando pesquisa e pesquisadores que trabalham com a perspectiva da 
Educação Popular e com outras abordagens de investigação comprometidas com a realidade social.

\section{Conclusão}

A Educação popular tem forte incidência na prática educativa dos educadores-docentes e sua repercussão no ensino, na extensão e na pesquisa no contexto acadêmico. Nas opções de linhas de pesquisas, existe uma relação de coerência quanto o reconhecimento dos princípios da Educação Popular na prática educativa desses sujeitos na descolonização do conhecimento de vertente hegemônica de ciência na universidade. Os educadores-docentes reconhecem que a participação dos discentes no processo de produção do conhecimento tem sido fundamental para seu desempenho como docente, uma vez que não existe vida docente sem uma presença ativa da vida discente.

Os educadores-docentes reconhecem a importância da dimensão ética da veracidade dos dados sobre a realidade social, nesse sentido, compreendem que a devolução sistematizada da pesquisa por meio de ações político-pedagógica de socialização dos achados junto aos sujeitos pesquisados como um aspecto metodológico fundamental da produção do conhecimento. Esse princípio investigativo, assegura a busca pela verdade como critério de uma produção cientifica rigorosa e socialmente comprometida com as questões sociais que envolvem soluções sob o ponto de vista do pesquisador, mas sobretudo, implica em uma análise dos sujeitos investigados.

Essa relação sujeito/sujeito inaugura uma pesquisa descolonizadora e instituidora de conhecimentos concretos para o mundo da vida, cuja soluções não podem ser reproduzidas apenas pelos esquemas de leitura do investigador, em uma reproduz do colonialismo intelectual que inferioriza a leitura dos sujeitos investigados. Na perspectiva da Educação Popular, as realidades pesquisadas têm sua própria estrutura de racionalidade, causalidade e inteligibilidade, portanto, os conhecimentos resultam de esquemas próprios de afirmação dos sujeitos populares e de seus contextos, que implica em superar esquemas externos que criam falseamento da realidade social.

Descolonizar a ciência, implica em projetar uma perspectiva de ensino universitário que seja capaz de reinventar a relação entre os saberes populares e os saberes científicos dentro e fora do espaço acadêmico. Nesse sentido, a contribuição da Educação Popular no processo de democratização da universidade e da ciência, exige, por um lado, um projeto de educação comprometido com uma prática educativa que promova a formação integral dos sujeitos 
discentes, rompendo com o individualismo e a competição produtiva para o capital. Por outro lado, implica em superar os esquemas eurocêntricos que separam o conhecimento universitário das questões urgentes e emergentes da sociedade. Nesse aspecto, a pesquisa, enquanto dimensão cientifica que atribui critério de cientificidade aos conhecimentos, assume um papel fundamental na produção contextualizada, que articulada ao ensino e a extensão são instrumentos metodológicos de reinvenção da vida universitária no desenvolvimento de um projeto de sociedade mais justa e humanamente sustentável.

\section{REFERÊNCIAS}

BORDA, O. F. La ciência y el Pueblo: nuevas reflexiones sobre la investigación-acción. In: CONGRESSO NACIONAL DE SOCIOLOGIA, 3., 1981, Bogotá. Anais [...]. Bogotá, 1981. Disponível em: http://upedagogica.edu.bo/wp-content/uploads/2015/12/D.-Fals-Borda-laciencia-y-el-pueblo.pdf. Acesso em: 10 ago. 2016.

BORDA, O. F.; MORA-OSEJO, L. E. A superação do eurocentrismo. Enriquecimento do saber sistêmico e endógeno sobre o nosso contexto tropical. In: SANTOS, B. S. (Org.).

Conhecimento prudente para uma vida decente: um discurso sobre as ciências sociais. São Paulo: Edições Afrontamento, 2003.

EQUIP. Educação popular: sujeitos políticos, participação popular, direitos humanos, cultura de paz e emancipação social. Recife: EQUIP, 2015.

FERNADES, F. O desafio educacional. São Paulo: Cortez: Autores Associados, 1989. (Educação Contemporânea)

FREIRE, P. R. N. Educação e Política. 1. ed. São Paulo: Paz e Terra, 2014.

HOLLIDAY, O. J. Sistematização de experiências: aprender a dialogar com os processos. 2007.

LEFEBVRE, H. Lógica formal/lógica dialética. Rio de Janeiro: Editora Civilização Brasileira, 1983.

SANTOS, B. S. Pela mão de Alice: o social e o político na pós-modernidade. 14. ed. São Paulo: Cortez, 2013.

SANTOS, B. S. Um discurso sobre as ciências. 6. ed. São Paulo: Cortez, 2010.

STRECK, D. R. (Org.). Dicionário Paulo Freire. 2. ed. rev. amp. Belo Horizonte: Autêntica Editora, 2010.

STRECK, D. R. et al. (Org.). Educação popular e docência. 1. ed. São Paulo: Cortez, 2014. (Coleção docência em formação: Educação de Jovens e Adultos/coordenação Selma Garrido Pimenta) 


\section{Como referenciar este artigo}

SILVA, M. S. P. Educação popular na prática docente universitária: epistemologia para uma ciência própria. Revista on line de Política e Gestão Educacional, Araraquara, v. 24, n. 3, p. $1541-1558$, set./dez. 2020. e-ISSN:1519-9029.

DOI: https://doi.org/10.22633/rpge.v24i3.14202

Submetido em: 01/06/2020

Revisões requeridas: $20 / 07 / 2020$

Aprovado em: 18/08/2020

Publicado em: 01/09/2020 